\title{
A new Slacks-Based Measure of Malmquist- Luenberger Index in the Presence of Undesirable Outputs
}

Behrouz Arabi , Susila Munisamy Doraisamy and Ali Emrouznejad

OMEGA 51(2015): 29-37

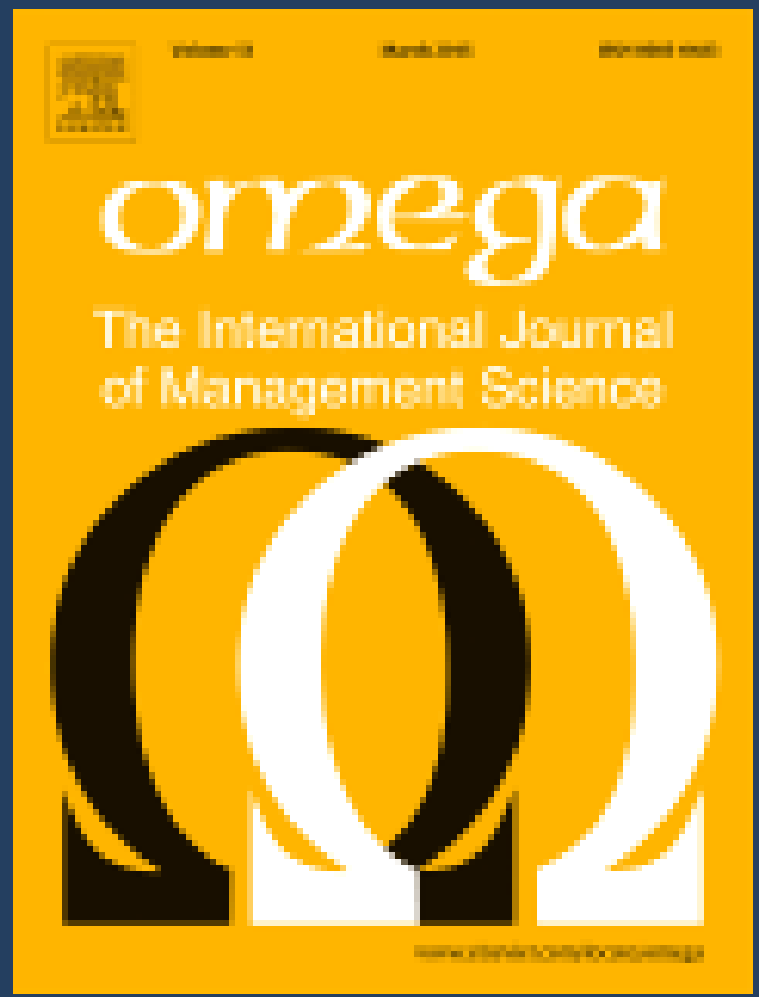

Arabi, B., S. Munisamy and A. Emrouznejad (2015), "A new Slacks-Based Measure of MalmquistLuenberger Index in the Presence of Undesirable Outputs," OMEGA, 51:29-37.

[Download1 or Download2] 
(C) 2014, Elsevier. Licensed under the Creative Commons Attribution-NonCommercial-NoDerivatives 4.0 International http://creativecommons.org/licenses/by-nc-nd/4.0/

\title{
A new Slacks-Based Measure of Malmquist-Luenberger Index in the Presence of Undesirable Outputs
}

\author{
Behrouz Arabi $^{\text {a1 }}$, Susila Munisamy Doraisamy ${ }^{\mathrm{b}}$, Ali Emrouznejad ${ }^{\mathrm{c}}$ \\ ${ }^{a}$ Institute of Graduate Studies, University of Malaya, Kuala Lumpur, Malaysia \\ ${ }^{\mathrm{b}}$ Faculty of Economics and Administration, University of Malaya, Kuala Lumpur, Malaysia \\ ${ }^{c}$ Aston Business School, Aston University, Birmingham, UK
}

\begin{abstract}
In the majority of production processes, noticeable amounts of bad byproducts or bad outputs are produced. The negative effects of the bad outputs on efficiency cannot be handled by the standard Malmquist index to measure productivity change over time. Toward this end, the Malmquist-Luenberger index (MLI) has been introduced, when undesirable outputs are present. In this paper, we introduce a Data Envelopment Analysis (DEA) model as well as an algorithm, which can successfully eliminate a common infeasibility problem encountered in MLI mixed period problems. This model incorporates the best endogenous direction amongst all other possible directions to increase desirable output and decrease the undesirable outputs at the same time. A simple example used to illustrate the new algorithm and a real application of steam power plants is used to show the applicability of the proposed model.
\end{abstract}

Keywords: Data Envelopment Analysis, Directional Distance Function, Eco-Efficiency Change

\section{Introduction}

One of the most popular methodologies for measuring efficiency of Decision Making Units (DMUs) is the non-parametric frontier mathematical programming approach called Data Envelopment Analysis (DEA). The concept behind DEA is measuring efficiency using production function as initiated in Farrell (1957), and later extended to cases with multiple-inputs multiple-outputs by Charnes et al. (1978), after which many empirical studies followed (Cook and Seiford, 2009; Emrouznejad et al., 2008; Seiford, 1996).

${ }^{1}$ Email: Beh.arabi@um.edu.my

Tel: 0060176481918 
In measuring efficiency normally inputs have to be minimized and outputs, in vice versa, are maximized. However, in some cases, some (good) outputs should be maximized or some (bad) outputs should be minimized simultaneously. Literature in DEA refers to bad outputs as undesirable factors (Seiford and Zhu, 2002). One can find a number of undesirable output examples in the empirical literature such as delayed flight (Coli et al., 2011), poverty rate (Bruni et al., 2011), patient deaths (Yawe and Kavuma, 2008), power interruptions and emissions such as SOx (Burnett and Hansen, 2008; Korhonen and Luptacik, 2004; Zhou et al., 2007), SO2, NOx and $\mathrm{CO}_{2}$ (Kortelainen and Kuosmanen, 2007; Sueyoshi and Goto, 2013; Tyteca, 1997), NOx (Oggioni et al., 2011; Tyteca, 1996) COx gases (Oude Lansink and Bezlepkin, 2003; Zaim and Taskin, 2000).

One of the variations in DEA studies is the incorporation of undesirable factors in the efficiency measurement, which is termed as eco-efficiency measurement. The incorporation of undesirable factors can be classified into two categories - direct and indirect approaches (Scheel, 2001). The indirect approaches change or customize undesirable factors to include them in the DEA model. On the other hand, the direct approaches treat undesirable as a regular input or output but modify the measurement model. There are several indirect approaches such as taking the additive inverse of undesirable factors (Berg et al., 1992), treating the undesirable output as an input (Tyteca, 1997), using multiplicative inverse (Knox Lovell et al., 1995), etc. In contrast, the direct approaches use some theoretical developments such as hyperbolic efficiency model (Boyd and McClelland, 1999), slacks-based measure (SBM) model (Tone, 2001), range adjusted measure (RAM) model (Zhou et al., 2006) and directional distance function (Chung et al., 1997; Färe and Grosskopf, 2000). Perhaps the most popular approach is the directional distance function (DDF) that has been used in many applications (Färe and Grosskopf, 2010a; Färe et al., 2007; PicazoTadeo et al., 2005) $)^{2}$. In spite of its popularity, DDF is known to encounter a problem of infeasibility when it is implemented in types of longitudinal studies to calculate MalmquistLuenberger index (MLI) (Chung et al., 1997; Färe et al., 2001). The infeasibility problem can occur in mixed period models when a DMU is located beyond the frontier of a different period. Hence, this paper aims to introduce a method to overcome the infeasibility problem of mixedperiod DDF models.

\footnotetext{
${ }^{2}$ A comprehensive overview about the ways of treating undesirable outputs can be found in Sahoo et al. (2011)
} 
The remainder of the paper is organized as follows. In the next section, related literature to DDF models is reviewed and the infeasibility problem is discussed. Section 3 introduces a model with an algorithm to enable DDF type Malmquist Index for handling DMUs, which are beyond the efficiency frontier. Section 4 illustrates the proposed algorithm using a numerical example on a real application of steam power plants over eight years. We discuss the results in Section 5 . Conclusions and suggestions for future research are given in Section 6.

\section{Background and motivation}

\subsection{Directional Distance Function}

In the DEA literature, one of the popular series of models introduced for measuring efficiency/inefficiency is Directional Distance Function (DDF). Using definition of distance Shephard et al. (1970) function incorporating undesirable outputs as below:

$$
D_{o}(x, y, b)=\inf \{\varphi:((y, b) / \varphi) \in P(x)\}
$$

where $x \in \mathbb{R}^{I}, y \in \mathbb{R}^{J}$ and $b \in \mathbb{R}^{K}$ are inputs, outputs and bad outputs of Decision Making Units (DMUs), and $\varphi$ denotes the expansion or contraction ratio of good and bad outputs, and $D_{o}$ expands good outputs and contracts bad outputs simultaneously as much as feasible. $P(x)$, production possibility set, is defined as:

$$
P(x)=\{(y, b): x \text { can produce }(y, b)\}
$$

However, Chung, et al. (1997) defines $D_{o}$ as:

$$
\vec{D}(x, y, b ; g)=\sup \{\theta \cdot(y, b)+\theta g \in P(x)\}
$$

where $\theta$ plays the same role as $\varphi$ in (1). Here, $g$ is a vector of directions and is defined as $g=(y,-b)$, using (3), good outputs can be expanded while bad outputs are contracted. Thus, weak disposability implies:

$$
(y, b) \in P(x) \text { and } 0 \leq \theta \leq 1 \text { imply }(\theta y, \theta b) \in P(x)
$$


But this contradicted with the concept indicting in (3) since weak disposability as in (4) means, to remain feasible, good outputs should be decreased with the same proportion as bad outputs ${ }^{3}$. Free disposability is also written as below:

$$
(y, b) \in P(x) \text { and } y^{\prime} \leq y \text { imply }\left(y^{\prime}, b\right) \in P(x)
$$

This also implies that good and bad outputs are freely disposable. In addition, it is also assumed that good and bad outputs are produced jointly namely "null-joint", which means, it is not possible to produce good output without producing any bad output.

Now according to Chung et al. (1997) $P(x)$ can be rewritten as below to be compatible with (2), (3), (4), and (5):

$$
\begin{gathered}
P(x)=\left\{(y, b): \sum_{n=1}^{N} z_{n} x_{i n} \leq x_{i o} \quad i=1,2, \ldots, I ; \quad \sum_{n=1}^{N} z_{n} y_{j n} \geq y_{j o}+\theta y_{j o}\right. \\
\left.j=1,2, \ldots, J ; \quad \sum_{n=1}^{N} z_{n} b_{k n}=b_{k o}-\theta b_{k o} \quad k=1,2, \ldots, K ; z_{n} \geq 0 ; n=1,2, \ldots, N\right\}
\end{gathered}
$$

here $z_{n}$ are intensity variables. According to (6) the following linear programming model can be used to find $\vec{D}(x, y, b ; g), g=(y,-b)$ :

$$
\vec{D}_{o}(x, y, b ; g)=\operatorname{Max} \theta
$$

\section{Subject to}

$$
\begin{aligned}
& \sum_{n=1}^{N} z_{n} x_{i n} \leq x_{i o} ; i=1,2, \ldots, I \\
& \sum_{n=1}^{N} z_{n} y_{j n} \geq y_{j o}+\theta y_{j o} ; j=1,2, \ldots, J \\
& \sum_{n=1}^{N} z_{n} b_{k n}=b_{k o}-\theta b_{k o} ; k=1,2, \ldots, K \\
& z_{n} \geq 0 ; n=1,2, \ldots, N
\end{aligned}
$$

Chambers et al. (1996) defined a similar model without considering undesirable outputs as formulated in Model (8) below:

\footnotetext{
${ }^{3}$ Economic implications of the weak disposability axiom is further discussed in Kuosmanen and Kazemi Matin (2011).
} 


$$
\vec{D}_{o}(x, y ; g)=\operatorname{Max} \theta
$$

Subject to

$$
\begin{aligned}
& \sum_{n=1}^{N} z_{n} x_{i n} \leq x_{i o}-\theta x_{i o} ; i=1,2, \ldots, I \\
& \sum_{n=1}^{N} z_{n} y_{j n} \geq y_{j o}+\theta y_{j o} ; j=1,2, \ldots, J \\
& z_{n} \geq 0 ; n=1,2, \ldots, N
\end{aligned}
$$

Here $g$ equals $(y,-x)$. It is worthwhile to note that, third series of constraints in Model (7) (which are corresponding to the bad outputs, $b$ 's) are similar to the first series of constraints in Model (8) (which are corresponding to inputs, $x$ 's) whereas in Model (7) third series of the constraints are equalities.

As indicated in Fukuyama and Weber (2009) and Zhou et al. (2012) a conventional DDF model may overestimate the efficiency when non-zero slacks appears in the efficiency measures, hence, a new generation of non-radial DDF model has been introduced to the DEA literature (Fukuyama et al., 2011) and have been successfully applied in many applications (Fukuyama and Weber, 2010; Mahlberg and Sahoo, 2011; Sahoo et al., 2011; Wang et al., 2013; Zhou et al., 2012). DDF models have also been applied in many disciplines including energy efficiency (Färe et al., 2007), assessment of banks (Barros et al., 2012), agriculture (Blancard et al., 2006). Recently Färe and Grosskopf (2013) have investigated affine data translation properties of DDF models. In section 3 we discuss the non-radial DDF Models in details.

\subsection{Malmquist-Luenberger index}

Based on the Malmquist index approach for efficiency and technology change, Chung et al. (1997) developed the Malmquist-Luenberger index (MLI). The MLI incorporates undesirable outputs, to evaluate productivity change when a longitudinal study is conducted ${ }^{4}$. In the same manner as Malmquist index which is calculated using a series of DEA models (Färe et al., 1994); the MLI deploys Directional Distance Function to solve various linear problems for decomposing MLI to technology and productivity change during the period of study.

\footnotetext{
${ }^{4}$ It should be noted that MLI is not the only index for evaluating productivity change in longitudinal studies in the presence of undesirable factors, researchers have introduced alternative Malmquist indexes, such as Malmquist CO2 emission performance index (MCPI) (Zhou et al., 2010) or Environmental Performance Index (EPI) (Kortelainen, 2008).
} 
Now we address how Model (7) can be used to calculate the following components of MLI in the longitudinal studies:

$$
M L_{t}^{t+1}=\left[\frac{\left(1+D_{o}^{t}\left(x^{t}, y^{t}, b^{t} ; y^{t},-b^{t}\right)\right)}{\left(1+D_{o}^{t+1}\left(x^{t+1}, y^{t+1}, b^{t+1} ; y^{t+1},-b^{t+1}\right)\right)} \times \frac{\left(1+D_{o}^{t+1}\left(x^{t}, y^{t}, b^{t} ; y^{t},-b^{t}\right)\right)}{\left(1+D_{o}^{t}\left(x^{t+1}, y^{t+1}, b^{t+1} ; y^{t+1},-b^{t+1}\right)\right)}\right]^{1 / 2}
$$

where $t=1, \ldots, T$ denotes periods of study. In other words, $D_{o}^{t+1}\left(x^{t}, y^{t}, b^{t} ; y^{t},-b^{t}\right)$, for example, represents the distance function for frontier in period $t+1$ while assessing a DMU from period $t$.

Therefore, the linear programs corresponding to $D_{o}^{t+1}\left(x^{t}, y^{t}, b^{t} ; y^{t},-b^{t}\right)$ and $D_{o}^{t}\left(x^{t+1}, y^{t+1}, b^{t+1} ; y^{t+1},-b^{t+1}\right)$ are named mixed period models, since the DMU under assessment and the frontier are from different periods. This can lead to an infeasibility problem, which is discussed further in Section 2.4.

\subsection{Slacks-Based Measure of Inefficiency}

The slacks-based measure of inefficiency as introduced by Tone (2001) is one the most common model applied in DEA. Tone (2010) has also deployed the slacks-based measure and its variations to measure productivity factors. Further, Färe and Grosskopf (2010b) have introduced the following model:

$$
\vec{D}_{O}(x, y, b)=\operatorname{Max} \alpha_{1}+\cdots+\alpha_{I}+\beta_{1}+\cdots+\beta_{J}
$$

Subject to

$$
\begin{aligned}
& \sum_{n=1}^{N} z_{n} x_{i n} \leq x_{i o}-\alpha_{i} .1 ; i=1,2, \ldots, I \\
& \sum_{n=1}^{N} z_{n} y_{j n} \geq y_{j o}+\beta_{j} .1 ; j=1,2, \ldots, J \\
& z_{n} \geq 0 ; \alpha_{i} \geq 0 ; \beta_{j} \geq 0 ; n=1,2, \ldots, N ; i=1,2, \ldots, I ; j=1,2, \ldots, J
\end{aligned}
$$

where, $\alpha_{1}, \ldots, \alpha_{I}$ and $\beta_{1}, \ldots, \beta_{J}$ are variable. Here we adapt Model (10) to include bad outputs as below: 


$$
\vec{D}_{o}(x, y, b)=\operatorname{Max} \beta_{1}+\cdots+\beta_{J}+\gamma_{1}+\cdots+\gamma_{K}
$$

Subject to

$$
\begin{aligned}
& \sum_{n=1}^{N} z_{n} x_{i n} \leq x_{i o} ; i=1,2, \ldots I ; \\
& \sum_{n=1}^{N} z_{n} y_{j n} \geq y_{j o}+\beta_{j} .1 ; j=1,2, \ldots, J \\
& \sum_{n=1}^{N} z_{n} b_{k n}=b_{k o}-\gamma_{k} .1 ; k=1,2, \ldots, K \\
& z_{n} \geq 0 ; \gamma_{k} \geq 0 ; \beta_{j} \geq 0 ; n=1,2, \ldots, N ; j=1,2, \ldots, J ; k=1,2, \ldots, K
\end{aligned}
$$

where, $\beta_{1}, \ldots, \beta_{J}$ and $\gamma_{1}, \ldots, \gamma_{K}$ are variable. Model (10) still suffers from infeasibility problem when it is applied for measuring Malmquist-Luenberger index. Later in Section 3 we customize this model in order to tackle the infusibility problem.

\subsection{The infeasibility problem}

As explained in the previous section, in order to calculate $M L_{t}^{t+1}$ or $M L_{t+1}^{t}$ a number of mixed period models have to be solved. This can lead to situations of infeasibility since in some cases one or more DMUs are located beyond the efficiency frontier and $g=(y,-b)$ or any other arbitrary directions, which are the same for all DMUs, cannot project those DMUs to the frontier ${ }^{5}$ (Chung et al., 1997). One can find an illustration of this problem in Färe et al. (2001). Many studies are capable of facing the same problem like what Chung et al. (1997), Färe et al. (2001), and Oh (2010) have done on Swedish pulp and paper industry, American coal-fired power plants, and 26 countries, respectively. The same problems can occur when super efficiency is calculated using DDF DEA models. Here it is important to note that, non-radial DDF with undesirable output are vulnerable of this infeasibility problem, when they are employed for ML index measurement (Wang et al., 2013).

To tackle this problem, a number of strategies have introduced. Färe et al. (2001) used just $t+1$ frontier as the reference technology, however in addition to the possibility of infeasibility which still exist when reference technology at period $t$ locates over $t+1$ frontier, this approach is an arbitrary strategy and just one reference technology is deployed. Färe et al. (2007) have

\footnotetext{
${ }^{5}$ This problem only happens in the presence of undesirable outputs and when DDF is employed to measure ML index. In the absence of undesirable outputs, constant return to scale (CRS) form of DDF models or Model (8), will always be feasible, even if it is used for super-efficiency measurement, see Ray (2007) and Chen et al. (2013).
} 
employed a joint technology reference from $t$ and $t+1$ period, where the data from $t+1$ is added to $t$ reference technology. Although this approach can eliminate the infeasibility problem but the frontier is arbitrary yet. By using global ML index of Oh (2010) the infeasibility problem does not occur, however again, global ML follows the approach that Färe et al. (2007) have taken for two consequent periods where they used meta frontier analysis.

Two simple examples, in Appendix, show inefficiency of other approaches introduced to tackle the infeasibility problem.

In the next section, we use DDF to introduce a method that the infeasibility would not happen.

\section{An approach to eliminate the infeasibility problem}

When a DMU falls beyond the frontier, there is a possibility of infeasibility when measuring the efficiency. This could be due two main reasons. First is the case that good outputs and bad outputs are expanding and contracting, respectively, with the same proportion. Second, because in a standard DDF model the same direction, $g=(y,-b)$, is applied to all DMU's. Thus, we define a new direction function based on a new set; $P^{\prime}(x)$, for the DMU's which lie above the boundary as below:

$$
\begin{aligned}
& P^{\prime}(x)=\{(y, b):(y, b) \notin P(x),(y, b) \geq 0\} \\
& \vec{D}_{o}^{\prime}(x, y, b ; g)=\inf \left\{|\tau|:(y, b)+\tau g \in P^{\prime}(x)\right\}
\end{aligned}
$$

where $\tau$ represents the minimum contraction of both good and bad outputs, which can project the DMU to the boundary. Therefore, we can reformulate model (11) for these DMUs as follows: 
$\vec{D}_{O}^{\prime}(x, y, b)=\operatorname{Min} \beta_{1}+\cdots+\beta_{J}+\gamma_{1}+\cdots+\gamma_{K}$

Subject to

$$
\begin{aligned}
& \sum_{n=1}^{N} z_{n} x_{i n} \leq x_{i o} ; i=1,2, \ldots, I \\
& \sum_{n=1}^{N} z_{n} y_{j n} \geq y_{j o}-\beta_{j} .1 ; j=1,2, \ldots, J \\
& \sum_{n=1}^{N} z_{n} b_{k n}=b_{k o}-\gamma_{k} .1 ; k=1,2, \ldots, K \\
& z_{n} \geq 0 ; \gamma_{k} \geq 0 ; \beta_{j} \geq 0 ; n=1,2, \ldots, N ; j=1,2, \ldots, J ; k=1,2, \ldots, K
\end{aligned}
$$

where $\alpha=\left\{\beta_{1}, \ldots, \beta_{J}, \gamma_{1}, \ldots, \gamma_{K}\right\}$. Model (14), unlike (11), seeks for the nearest direction toward frontier, since the DMUs below and above the frontier follows different paradigms. For the DMUs located below the frontier, those closer to the frontier are evaluated as being more efficient, however for the DMUs above the frontier regarded as being less efficient. In other words, in this case the DMU located furthest away from the frontier is the most efficient.

According to Färe and Grosskopf (2010a) for finding the direction vector we can reformulate Model (13) to the following model:

$$
\vec{D}_{o}^{\prime}(x, y, b)=\operatorname{Min} \eta
$$

\section{Subject to}

$$
\begin{aligned}
& \sum_{n=1}^{N} z_{n} x_{i n} \leq x_{i o} ; i=1,2, \ldots ; \\
& \sum_{n=1}^{N} z_{n} y_{j n} \geq y_{j o}-g_{y j} . \eta ; j=1,2, \ldots, J \\
& \sum_{n=1}^{N} z_{n} b_{k n}=b_{k o}-g_{b k} . \eta ; k=1,2, \ldots, K \\
& \sum_{j=1}^{J} g_{y j}+\sum_{k=1}^{K} g_{b k}=1 \\
& \quad z_{n} \geq 0 ; g_{y k} \geq 0 ; g_{b j} \geq 0 ; n=1,2, \ldots, N ; j=1,2, \ldots, J ; k=1,2, \ldots, K
\end{aligned}
$$

Let $g_{y j} . \eta=\beta_{j}$ and $g_{y k} . \eta=\beta_{k}$ it can easily be verified that Model (14) and Model (15) are equivalent, therefore optimal solution of Model (14) equals $\eta^{*}$ for an identical DMU under assessment. 
Now, we indicate how the optimal direction for Model (15), (or later for Model (19)) can be obtained through solving Model (14), (or later through Model (11)). It is trivial that, if DMUo, is placed on the frontier then $G=\left(g_{y 1}, \ldots, g_{y J}, g_{b 1}, \ldots, g_{b K}\right)$, the direction vector, can be any direction, otherwise by solving Model (13) and assuming $g_{y j} \cdot \eta^{*}=\beta_{j}^{*}$ and $g_{b k} \cdot \eta^{*}=\beta_{k}^{*}$ we conclude:

$$
\eta^{*}=\frac{\beta_{1}^{*}}{g_{y 1}}=\frac{\beta_{2}^{*}}{g_{y 2}}=\cdots=\frac{\beta_{J}^{*}}{g_{y J}}=\frac{\gamma_{1}^{*}}{g_{b 1}}=\frac{\gamma_{2}^{*}}{g_{b 2}}=\cdots=\frac{\gamma_{K}^{*}}{g_{b K}}
$$

Hence,

$$
\beta_{1}^{*} \cdot g_{y 2}=\beta_{2}^{*} \cdot g_{y 1}, \beta_{2}^{*} \cdot g_{y 3}=\beta_{3}^{*} \cdot g_{y 2}, \ldots, \beta_{J}^{*} \cdot g_{b 1}=\gamma_{1}^{*} \cdot g_{y J}, \ldots, \gamma_{K-1}^{*} \cdot g_{b K}=\gamma_{K}^{*} \cdot g_{b K-1}
$$

Next we achieve:

$$
\begin{gathered}
\beta_{1}^{*} \cdot g_{y 2}-\beta_{2}^{*} \cdot g_{y 2}=0, \\
\beta_{2}^{*} \cdot g_{y 3}-\beta_{3}^{*} \cdot g_{y 2}=0, \\
\cdots, \\
\beta_{J}^{*} \cdot g_{b 1}-\gamma_{1}^{*} \cdot g_{y J}=0, \\
\ldots, \\
\gamma_{K-1}^{*} \cdot g_{b K}-\gamma_{K}^{*} \cdot g_{b K-1}=0 \\
\sum_{j=1}^{J} g_{y j}+\sum_{k=1}^{K} g_{b k}=1
\end{gathered}
$$

Where (18) is a system of equation with first similar $J+K-1$ equations and $J+K$ unknowns. Thus, together with $\sum_{j=1}^{J} g_{y j}+\sum_{k=1}^{K} g_{b k}=1$ we have $J+K$ equations and $J+K$ unknowns with first $J+K-1$ pairwise linearly independent equations. Furthermore, no linear combination of the first $J+K-1$ equations can generate the last equation, since first $J+K$ equations have zero in their RHS but the last equation has unity in the same place. Therefore, this is a system of linear equations with a unique solution, which is $G=\left(g_{y 1}, \ldots, g_{y J}, g_{b 1}, \ldots, g_{b K}\right)$. As a result, by solving (14) and (18) we can achieve optimal directions.

Here, we illustrate this case with a very simple example of single input and two outputs - one good and one bad. Here efficiency score is $\left(1-D^{\prime}\right)$. 
Table 1: A simple example, data and efficiency scores

\begin{tabular}{cccccccccc}
\hline DMU & \multicolumn{2}{c}{ Data } & \multicolumn{2}{c}{ Efficiency Score } \\
\hline & \multicolumn{2}{c}{ Good Output } & \multicolumn{2}{c}{ Bad Output } & \multicolumn{2}{c}{ Model (7) } & \multicolumn{2}{c}{ Model (11) } & \multicolumn{2}{c}{ Model (14) } \\
using MLIA
\end{tabular}

*Na refers to not available

Figure 1 is a graphical presentation of Table 1, where $P(x)$ is the production possibility set, in period $t$, and $D V_{t+1,1,7}=\left(y_{t+1,1,}-b_{t+1,1}\right)=(4,-4)$ and $D V_{t+1,5,7}=\left(y_{t+1,5,}-b_{t+1,5}\right)=(3.5,-3.5)$ are the direction vectors assigned to $\mathrm{DMU}_{1}$ and $\mathrm{DMU}_{5}$ in period $t+1$ by model (7), respectively. In addition, in Figure 1, $D V_{t+1,5,11}=\left(g_{y},-g_{b}\right)=(0,-1)$ and $D V_{t+1,5,14}=\left(g_{y},-g_{b}\right)=(-0.5,-0.5)$ are the direction vectors corresponding to $\mathrm{DMU}_{5}$ in period $t+1$ calculated by Model (11) and Model (14), respectively ${ }^{6}$. Here $D V_{t+1,1}, 7$, refers to the direction vector corresponding to the period $t+1$.

As can be seen in this Figure 1, by deploying Model (7), the $D V_{t+1,5}, 7$ does not intersect $P(X)$. Therefore Model (7) is infeasible for this DMU; while deploying Model (14), using (-0.5,-0.5) as the optimal direction, $\mathrm{DMU}_{t+1} 5$ is drawn to $\mathrm{DMU}_{t} 4$ on the border of $P(X)$ and the model is feasible for this DMU.

Now consider calculating $D_{o}^{t}\left(x^{t+1}, y^{t+1}, b^{t+1}\right)$ using Model (7), we get infeasible solution for $\mathrm{DMU}_{t+1}$ 5, while using Model (14) the efficiency score of 1.25 is achieved. In this particular case, Model (11) is feasible for $\mathrm{DMU}_{t+1} 5$ and it is projected to $\mathrm{DMU}_{t} 3$. However, as can be seen in the Figure 1, Model (14) evaluates its distance value in a more reasonable way since the distance to the frontier is minimized.

Focusing on Figure 1, one can see that Model (7) and Model (11) yield infeasible solution for $\mathrm{DMU}_{t+1} 1$, since for model $(7),(4,-4)$ does not intersect $P(x)$ and Model (11) cannot find any feasible direction to intersect $P(x)$. However, employing Model (14) the projected point is $\mathrm{DMU}_{t} 4,-0.5$ and 1.5 can be achieved for the distance value and the efficiency score, respectively.

\footnotetext{
${ }^{6}$ According to equation (16) or (17) $g_{y}=\eta^{*} / \beta_{j}^{*},-g_{b}=\eta^{*} / \beta_{k}^{*}$, where $\eta^{*}$ is the corresponding optimal value of Model (14) which equals to the same amount of Model (11) for each DMU, since Model (14) and Model (11) are equivalent.
} 


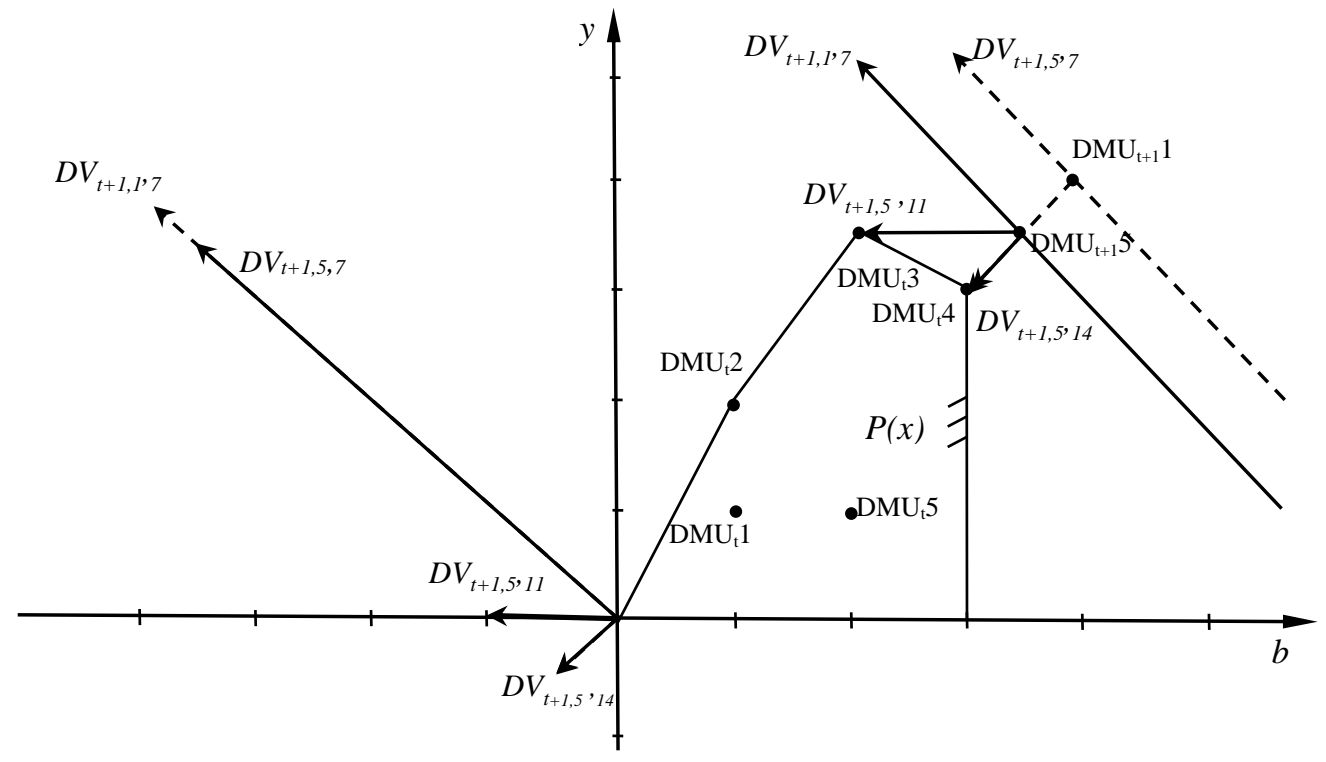

Figure 1: A graphical presentation of DMUs in Table 1

Thus, we propose the following 3 steps algorithm to avoid infeasibility problem in calculating MLI:

1. Examine if there are DMUs that are located beyond the efficiency frontier

2. If so, deploy Model (14) to calculate $D_{o}^{t}\left(x^{t+1}, y^{t+1}, b^{t+1}\right)$, and $D_{o}^{t+1}\left(x^{t}, y^{t}, b^{t}\right)$ for the same DMUs. ${ }^{7}$

3. Otherwise deploy Model (11) to compute $D_{o}^{t}\left(x^{t}, y^{t}, b^{t}\right), D_{o}^{t}\left(x^{t+1}, y^{t+1}, b^{t+1}\right)$, $D_{o}^{t+1}\left(x^{t}, y^{t}, b^{t}\right)$ and $D_{o}^{t}\left(x^{t+1}, y^{t+1}, b^{t+1}\right)$ for all DMUs.

In the rest of this paper we refer to this algorithm as MLIA (Malmquist-Luenberger Index Algorithm). It also should be noted that the same approach can be applied to eliminate the similar infeasibility problem in MLI measurement using non-radial DDF models by applying Model (14) for the DMUs that are located beyond the frontier when a non-radial DDF model is employed to measure ML index.

\subsection{Feasibility conditions considerations}

One last thing to be proved is the model feasibility. Toward this aim, we have the following theorem:

${ }^{7} D_{o}^{t}\left(x^{t}, y^{t}, b^{t}\right)$ and $D_{o}^{t+1}\left(x^{t+1}, y^{t+1}, b^{t+1}\right)$ are calculated using (11) 
Theorem: If $\left(y_{1}, b_{1}\right) \in P^{\prime}(x)$ then Model (14) is feasible for $\left(y_{1}, b_{1}\right)$.

Proof: To prove this, it is sufficient if we find at least one vector like $(Z, B, \digamma)$, which satisfies all constraints in Model (14). In order to do so, let us assume $P(x) \neq \varnothing$ so there is at least one $\left(y_{0}\right.$, $\left.b_{0}\right) \in P(x)$ and $\left(y_{0}, b_{0}\right)$ is on the frontier, so if we take $\left(y_{1}, b_{1}\right) \in P^{\prime}(x)$ then $y_{1}>y_{0}$ or $b_{1} \neq b_{0}$. In fact,

since $(0,0) \in P(x)$ (null jointness property), $b_{1} \neq b_{0}$ result in $b_{1}>b_{0}$, otherwise $0<b_{1}<b_{0}$ which means $0<b_{1}$. Hence, if $y_{1}>y_{0}$ or $b_{1}>b_{0}$, if $y_{1}=\left(y_{11}, . ., y_{J_{1}}\right)$ and $b_{1}=\left(b_{11}, . ., b_{K 1}\right)$, there exist at least one $y_{j 1}>y_{j 0}$ or $b_{k 1}>b_{k 0}$ or if $0<b_{1}<b_{0}$ then $0<b_{k 1}<b_{k 0}$. Thus, $\left(0, y_{1}, b_{1}\right)$ with $y_{1} \neq 0$ and $b_{1} \neq 0$ satisfies all the constraints, means model (14) is feasible.

Therefore, if Model (11) (or even Model (7)) has an infeasible solution for any particular DMU, using model (14) we can find its distance to the frontier and consequently calculate inefficiency, efficiency, and MLI measures.

\subsection{Advantages of the new slacks-based models}

Similar to Model (14) (and Model (15)), it can simply be shown that Model (11) is equivalent to the following model:

$$
\begin{aligned}
& \vec{D}_{O}(x, y, b)=\operatorname{Max} \eta \\
& \text { Subject to } \\
& \sum_{n=1}^{N} z_{n} x_{i n} \leq x_{i o} ; i=1,2, \ldots ; \\
& \sum_{n=1}^{N} z_{n} y_{j n} \geq y_{j o}+g_{y j} . \eta ; j=1,2, \ldots, J \\
& \sum_{n=1}^{N} z_{n} b_{k n}=b_{k o}-g_{b k} . \eta ; k=1,2, \ldots, K \\
& \sum_{j=1}^{J} g_{y j}+\sum_{k=1}^{K} g_{b k}=1 \\
& z_{n} \geq 0 ; g_{y k} \geq 0 ; g_{b j} \geq 0 ; n=1,2, \ldots, N ; j=1,2, \ldots, J ; k=1,2, \ldots, K
\end{aligned}
$$

With the same proof as in the previous section, it can be shown that $\mathrm{G}=\left(g_{y 1}, \ldots, g_{y j}, g_{b 1}, \ldots, g_{b K}\right)$ is an optimal direction which can be calculated by solving Model (11). In other words, G projects each inefficient DMU to the farthest point in the feasible region by increasing the good outputs and decreasing the bad ones, simultaneously. In this sense, the new models, Model (11) and 
Model (14), give a better value of inefficiency in comparison to the other conventional DDF models, which employ $g=(y,-b)$ as an arbitrary direction.

Model (19) and its equivalent Model (11), are seeking for the best direction to project the under

assessment inefficient DMU to the farthest point on the efficient frontier by simultaneously expanding the good outputs and contracting the bad outputs, proportionally, whereas non-radial DDF models minimize the slacks remained in the efficiency by expanding the goods and contracting the bads, simultaneously, however non-proportionally. Model (19) and Model (11), find the optimal direction endogenously (see Equations 16, 17, and 18). These models are more proper for the situations with less information about the technology. However non-radial models like those are employed by Zhou et al. (2012) and Wang et al. (2013) are more appropriate for efficiency measurement in the presence of comprehensive information and when the stress is on compliance with the exogenous rules instead of flexibility of efficiency measurement models.

Next section exhibits applicability of MLIA and Model (11) and (14) by applying them in a real application.

\section{An Application in Power Plants}

To illustrate applicability of MLIA, we deploy this algorithm to calculate ML productivity index for 18 steam power plants in Iran over an eight years period of restructuring to provide analytical reports for power industry authorities of the restructuring success or failure. The steam power plants have a $28 \%$ contribution in the countrywide generation of electricity. Therefore these reports are necessary since one of the main objectives of restructuring in Iran's power industry is to enhance the efficiency of power facilities (Ghazizadeh et al., 2007). In line with this, inputs and outputs of our models have been chosen as Table 2 . 
Table 2: Definitions of input-output variables

\begin{tabular}{|c|c|}
\hline Inputs & Definition \\
\hline 1. Installed or Effective Capacity & $\begin{array}{l}\text { This factor which is used as a proxy for capital is nameplate capacity in Mega } \\
\text { Watts. This value is the summation of all operational turbines capacity which } \\
\text { can be found in their catalog. } \\
\text { Effective capacity is the actual power of the power plants which can be } \\
\text { generated by its turbines.* }\end{array}$ \\
\hline 2. Fuel Consumption & $\begin{array}{l}\text { Since a heat turbine can consume different types of fuel and each fuel has } \\
\text { different heating value, this factor is calculated by the summation of the calorie } \\
\text { which each type of consumed fuel could produce in a year.* }\end{array}$ \\
\hline Outputs & Definition \\
\hline $\begin{array}{l}\text { Undesirable: } \\
\text { 1. SO2, Nox, Cox emission }\end{array}$ & Tones of emission factors which are produced by a power plant in a year ** \\
\hline $\begin{array}{l}\text { 2.Operational availability/ Deviation } \\
\text { from Generation plan }\end{array}$ & $\begin{array}{l}\text { It is the summation of daily rates of generated energy to the energy which was } \\
\text { supposed to be generated by national dispatching in peak hour in a year, Mega } \\
\text { Watt Hours. } *_{* *}\end{array}$ \\
\hline Desirable: Generated Energy & $\begin{array}{l}\text { Amount of Mega Watt Hours energy which has been generated by a power plant } \\
\text { and has been injected to national power network in a year* }\end{array}$ \\
\hline
\end{tabular}

This selection is based on a comprehensive literature review on the previous similar studies. Golany et al. (1994), one of the first papers using DEA as efficiency measurement tool, chose installed capacity, fuel consumption and manpower as inputs, while the bad outputs were SO2 emission and deviation from operational parameters and the good outputs were generated power and operational availability. In another study, Athanassopoulos et al. (1999) took fuel, controllable costs and capital expenditure as inputs; generated pollution and accidents incurred as bad outputs, and electricity produced and plant availability as good outputs while (Burnett and Hansen, 2008) deployed capital, fuel costs, and operating costs as inputs, $\mathrm{SO} 2$ emission as bad output and generated power as good output. In a very similar study to ours, Färe et al. (2005) employed labor, installed capacity, and fuel as inputs and $\mathrm{SO} 2$ emission and generated power as undesirable and desirable outputs, respectively. More recently, Sueyoshi and Goto (2011) used generation capacity, number of employees, coal, oil, and $\mathrm{LNG}^{9}$ as inputs, $\mathrm{CO} 2$ emission as bad output and generation as good output for their study.

\footnotetext{
${ }^{8}$ Iran Generation, Transmission, and Distribution Holding Company

${ }^{9}$ Liquefied Natural Gas
} 
Table 3: Results for Deploying Model (14) to tackle infeasibility problem in Model (10)

\begin{tabular}{|c|c|c|c|c|c|c|c|c|c|c|c|c|c|c|c|}
\hline \multirow{3}{*}{$\begin{array}{l}\text { Power } \\
\text { Plants } \\
\text { Codes } \\
\end{array}$} & \multicolumn{7}{|c|}{$D_{o}^{t}\left(x^{t+1}, y^{t+1}, b^{t+1}\right)$ Results of Model (11) } & \multirow{3}{*}{$\begin{array}{l}\text { Power } \\
\text { Plants } \\
\text { Codes }\end{array}$} & \multicolumn{7}{|c|}{$D_{o}^{t}\left(x^{t+1}, y^{t+1}, b^{t+1}\right)$ Results of Model (14) using MLIA } \\
\hline & 2003- & $2004-$ & $2005-$ & 2006- & $2007-$ & $2008-$ & 2009- & & $2003-$ & & $2005-$ & 2006- & & $2008-$ & 2009- \\
\hline & 2004 & 2005 & 2006 & 2007 & 2008 & 2009 & 2010 & & 2004 & 2005 & 2006 & 2007 & 2008 & 2009 & 2010 \\
\hline St_1 & 0.089 & 0.294 & 0.159 & 0.169 & 0.107 & 0.459 & 0.214 & St_1 & 0.089 & 0.294 & 0.159 & 0.169 & 0.107 & 0.459 & 0.214 \\
\hline $\mathrm{St} \_2$ & 0.360 & 0.348 & $\mathrm{Na}$ & $\mathrm{Na}$ & 0.354 & 0.674 & 0.504 & St_2 & 0.360 & 0.348 & -0.020 & -0.002 & 0.354 & -0.036 & 0.504 \\
\hline St_3 & 0.177 & 0.162 & 0.108 & 0.267 & 0.411 & 0.182 & 0.150 & St_3 & -0.014 & 0.162 & -0.017 & 0.267 & 0.411 & 0.182 & 0.150 \\
\hline St_4 & 0.440 & 0.465 & 0.391 & 0.418 & 0.497 & 0.653 & 0.775 & St_4 & 0.440 & 0.465 & 0.391 & 0.418 & 0.497 & 0.653 & 0.775 \\
\hline St_5 & 0.220 & 0.161 & 0.291 & 0.188 & 0.029 & 0.196 & 0.184 & St_5 & 0.220 & -0.002 & 0.291 & 0.000 & -0.014 & 0.000 & -0.001 \\
\hline St_6 & $\mathrm{Na}$ & 0.073 & 0.169 & 0.141 & 0.115 & $\mathrm{Na}$ & 0.026 & St_6 & -0.093 & 0.073 & 0.169 & 0.141 & 0.115 & -0.321 & 0.026 \\
\hline St_7 & 0.088 & 0.150 & 0.160 & 0.304 & 0.055 & 0.095 & 0.165 & St_7 & 0.088 & 0.150 & 0.160 & 0.304 & 0.055 & 0.095 & 0.165 \\
\hline St_8 & 0.074 & 0.155 & 0.101 & 0.239 & 0.203 & 0.147 & 0.131 & St_8 & 0.074 & -0.001 & 0.101 & 0.239 & 0.203 & 0.147 & -0.005 \\
\hline St_9 & $\mathrm{Na}$ & 0.732 & 0.380 & $\mathrm{Na}$ & $\mathrm{Na}$ & $\mathrm{Na}$ & 0.297 & St_9 & -0.004 & 0.000 & -0.001 & -0.043 & -0.032 & -0.020 & -0.005 \\
\hline St_10 & $\mathrm{Na}$ & $\mathrm{Na}$ & $\mathrm{Na}$ & $\mathrm{Na}$ & $\mathrm{Na}$ & 0.085 & 0.122 & St_10 & -0.025 & -0.005 & -0.013 & -0.025 & -0.019 & 0.085 & 0.122 \\
\hline St_11 & 0.163 & 0.278 & 0.201 & 0.199 & 0.147 & 0.141 & 0.192 & St_11 & -0.007 & 0.278 & 0.201 & 0.199 & 0.147 & 0.141 & -0.003 \\
\hline St_12 & $\mathrm{Na}$ & 0.144 & 0.186 & $\mathrm{Na}$ & $\mathrm{Na}$ & 0.096 & 0.175 & St_12 & -0.101 & 0.144 & 0.186 & -0.223 & -0.114 & 0.096 & 0.175 \\
\hline St_13 & 0.095 & $\mathrm{Na}$ & 0.222 & 0.138 & $\mathrm{Na}$ & $\mathrm{Na}$ & 0.091 & St_13 & 0.095 & -0.033 & 0.222 & 0.138 & -0.016 & -0.011 & 0.091 \\
\hline St_14 & 0.598 & 0.558 & & 0.545 & 0.369 & 0.275 & 0.236 & St_14 & -0.159 & -0.001 & 04 & -0.148 & -0.006 & -0.013 & -0.036 \\
\hline St_15 & 0.164 & 0.049 & 0.427 & 0.382 & 0.294 & 0.222 & 0.299 & St_15 & 0.164 & -0.012 & 0.000 & 0.382 & -0.027 & 0.222 & 0.000 \\
\hline St_16 & 0.108 & 0.069 & 0.154 & $\mathrm{Na}$ & 0.108 & $\mathrm{Na}$ & 117 & St_16 & 0.108 & 0.069 & 0.154 & -0.180 & 0.108 & -0.002 & 0.117 \\
\hline St_17 & 0.317 & 0.169 & 0.310 & 0.254 & 0.139 & 0.277 & 0.319 & St_17 & 0.317 & 0.169 & 0.310 & 0.254 & 0.139 & 0.277 & 0.319 \\
\hline \multirow[t]{2}{*}{ St_18 } & 0.182 & $\mathrm{Na}$ & $\mathrm{Na}$ & $\mathrm{Na}$ & $\mathrm{Na}$ & 0.032 & 44 & St_18 & 0.182 & -0.018 & -0.007 & -0.014 & -0.240 & 0.032 & 0.344 \\
\hline & \multicolumn{7}{|c|}{$D_{o}^{t+1}\left(x^{t}, y^{t}, b^{t}\right)$ Results of Model (10) } & & \multicolumn{7}{|c|}{$D_{o}^{t+1}\left(x^{t}, y^{t}, b^{t}\right)$ Results of Model (13) using MLIA } \\
\hline St_1 & 0.192 & 0.080 & 0.249 & 0.155 & 0.146 & 0.183 & 0.429 & St_1 & 0.192 & 0.080 & 0.249 & 0.155 & 0.146 & 0.183 & 0.429 \\
\hline St_2 & 0.277 & 0.366 & 0.335 & $\mathrm{Na}$ & 0.161 & 0.373 & 0.667 & St_2 & 0.277 & 0.366 & 0.335 & -0.026 & 0.161 & 0.373 & -0.023 \\
\hline St_3 & 0.341 & 0.178 & 0.155 & 0.102 & 0.261 & 0.426 & 0.137 & St_3 & 0.341 & 0.178 & 0.155 & -0.015 & 0.261 & 0.426 & -0.020 \\
\hline St_4 & 0.449 & 0.469 & 0.406 & 0.411 & 0.387 & 0.576 & 0.619 & St_4 & -0.013 & 0.469 & 0.406 & 0.411 & 0.387 & 0.576 & 0.619 \\
\hline St_5 & $\mathrm{Na}$ & 0.226 & 0.147 & 0.294 & 0.182 & 0.056 & 0.188 & St_5 & -0.017 & 0.226 & -0.003 & 0.294 & 0.182 & -0.017 & 0.000 \\
\hline St_6 & $\mathrm{Na}$ & $\mathrm{Na}$ & 0.038 & 0.179 & 0.124 & 0.174 & $\mathrm{Na}$ & St_6 & -0.009 & -0.236 & 0.038 & 0.179 & 0.124 & 0.174 & -0.215 \\
\hline St_7 & 0.144 & 0.108 & 0.115 & 0.171 & 0.291 & 15 & 0.125 & St_7 & 0.144 & 0.108 & 0.115 & 0.171 & 91 & 15 & 0.125 \\
\hline St_8 & 0.127 & 0.092 & 0.131 & 0.112 & 0.223 & 0.250 & 0.170 & St_8 & -0.010 & 0.092 & -0.004 & -0.028 & 0.223 & 0.250 & 0.000 \\
\hline St_9 & $\mathrm{Na}$ & $\mathrm{Na}$ & $\mathrm{Na}$ & 0.294 & $\mathrm{Na}$ & 0.304 & $\mathrm{Na}$ & St_9 & -0.075 & -0.032 & -0.024 & 0.294 & -0.025 & -0.001 & -0.066 \\
\hline St_10 & $\mathrm{Na}$ & 0.022 & $\mathrm{Na}$ & $\mathrm{Na}$ & $\mathrm{Na}$ & 0.088 & 0.058 & St_10 & -0.010 & 0.022 & -0.101 & -0.027 & -0.025 & 0.088 & 0.058 \\
\hline St_11 & 0.250 & 0.161 & 0.276 & 0.201 & 0.199 & 0.150 & 0.144 & St_11 & 0.250 & -0.006 & 0.276 & 0.000 & 0.199 & 0.150 & -0.005 \\
\hline St_12 & 0.110 & $\mathrm{Na}$ & $\mathrm{Na}$ & 0.174 & 0.009 & 0.139 & 0.160 & St_12 & -0.022 & -0.260 & -0.184 & 0.174 & 0.009 & -0.013 & 0.160 \\
\hline St_13 & $\mathrm{Na}$ & 0.141 & $\mathrm{Na}$ & 0.014 & 0.116 & 0.127 & $\mathrm{Na}$ & St_13 & -0.034 & 0.141 & -0.197 & 0.014 & 0.116 & 0.127 & -0.004 \\
\hline St_14 & 0.489 & 0.599 & 0.557 & 0.453 & 0.545 & 0.371 & 0.278 & St_14 & -0.003 & -0.059 & -0.146 & -0.005 & -0.278 & -0.149 & -0.057 \\
\hline St_15 & 0.070 & 0.167 & 0.046 & 0.423 & 0.381 & 0.307 & $\mathrm{Na}$ & St_15 & -0.004 & 0.000 & -0.003 & -0.002 & -0.002 & -0.011 & -0.016 \\
\hline St_16 & $\mathrm{Na}$ & 0.132 & $\mathrm{Na}$ & 0.130 & 0.013 & 0.144 & 0.033 & St_16 & -0.028 & 0.132 & -0.106 & 0.130 & 0.013 & 0.144 & 0.033 \\
\hline St_17 & 0.298 & 0.333 & 0.152 & 0.291 & 0.249 & 0.179 & 0.298 & St_17 & 0.298 & 0.333 & 0.152 & 0.291 & 0.249 & 0.179 & 0.298 \\
\hline St_18 & $\mathrm{Na}$ & 0.047 & $\mathrm{Na}$ & 0.051 & 0.196 & $\mathrm{Na}$ & $\mathrm{Na}$ & St_18 & -0.095 & 0.047 & -0.016 & -0.012 & 0.196 & -0.040 & -0.101 \\
\hline
\end{tabular}

We ran the models to find MLI for steam power plants over an eight years period, from 2003 to 2010, of restructuring in Iran power industry but we just exhibit the results for two mixed period DEA models to calculate $D_{o}^{t+1}\left(x^{t}, y^{t}, b^{t}\right)$ and $D_{o}^{t}\left(x^{t+1}, y^{t+1}, b^{t+1}\right)$ in Table 3. To maintain confidentiality of the results, power plants names have been coded to St_1 to St_18. In order to distinguish between the DMU which have been located beyond the frontier we have shown their distance value by negative sign.

As can be observed from the right hand side of Table 3, the infeasibility problem is fully tackled in the power plant case. Every infeasible solution is denoted by ' $\mathrm{Na}$ '. As can be seen in Table 3, the corresponding value for each ' $\mathrm{Na}$ ' in the left hand side of the Table is a negative value on the right hand side. Moreover, one can see some feasible values in the left hand side obtain a negative value in the right hand side; these are the DMUs that are located over the frontier and 
had feasible solution using Model (11). However, as we justified in Section 3, it is more reasonable if model (14) is deployed to measure the distance value for them. Furthermore, in order to calculate MLI we have $\left(1+D_{o}^{t+1}\left(x^{t}, y^{t}, b^{t}\right)\right)$ and $\left(1+D_{o}^{t}\left(x^{t+1}, y^{t+1}, b^{t+1}\right)\right)$ which are calculated using mixed period DEA models; the negative sign for the DMUs locating beyond the frontier make the value less than unity and for other DMUs greater or equals to 1.

\section{Discussion}

Focusing on Table 3, one can see that every infeasibility denoted by ' $\mathrm{Na}$ ' in left side of the table has been eliminated by MLIA, so the model in addition to the algorithm can be deployed for studies using MLI to evaluate the trend of productivity change over a period.

It is also clear in Table 3 that every infeasibility has been replaced with a negative value for the distance function. To calculate the eco-efficiency value we use $1-D$, hence we obtain a value more than unity for these DMUs acting better than the contemporary technology or have been located beyond the eco-efficiency frontier. In addition, Model (14) gives a reasonable value for the eco-efficiency, since based on its nature Model (14) assigns a larger eco-efficiency score to DMUs which are located further away from the frontier.

Moreover, as mentioned in Section 3, by using Model (14) and Model (15) one can determine the optimal direction for every DMU. Figure 1 shows these directions graphically, and depict which direction a DMU can be projected to the frontier of Model (11) and Model (14). However, using Model (14), the DMU has a choice to choose different directions and to project to different frontiers in order to minimize the distance and obtain the best eco-efficiency scores.

Finally, the MLIA, Model (11), and Model (14) together, not only they solve the problem of infeasibility and give a reasonable value for eco-efficiency, but also they are not of arbitrary choice of the frontier for the mixed period problems, as proposed in Section 2.4. Therefore, the algorithm together with the model can provide a reliable approach for the further studies involving distance functions with mixed period mathematical programming models. 


\section{Conclusions}

The infeasibility problem is prevalent in Malmquist-Luenberger Index (MLI) evaluation process. Researchers have taken a number of strategies to overcome it but all has been arbitrary. In this paper, we introduced a model as well as an algorithm based on a slacks-based measure, which can eliminate this infeasibility problem as well as render a non-arbitrary frontier. The new model incorporates an optimal direction to increase good outputs and decrease bad outputs, simultaneously. Deploying the introduced model, we presented an algorithm for finding efficiency scores of mixed period problems. The proposed algorithm is applicable for both radial and non-radial DDF models. Using a simple example we illustrated the algorithm and its workability. To show the applicability of the new MLI algorithm was implemented on a power plant panel dataset, the results clearly demonstrated that the infeasibility problem was successfully eliminated.

\section{Acknowledgment}

The authors would like to thank Professor Ben Lev, the editor of OMEGA and the anonymous reviewers for their insightful comments and suggestions, we also extend our warm thanks to Dr. Carl Pasurka from George Mason University, School of Business and Policy, who provided us with the attachments and explanations of their previous studies.

\section{References}

Aparicio, J., Pastor, J. T., \& Zofio, J. L. (2013). On the inconsistency of the MalmquistLuenberger index. European Journal of Operational Research, 229(3), 738-742.

Athanassopoulos, A. D., Lambroukos, N., \& Seiford, L. (1999). Data envelopment scenario analysis for setting targets to electricity generating plants. European journal of operational research, 115(3), 413-428.

Barros, C. P., Managi, S., \& Matousek, R. (2012). The technical efficiency of the Japanese banks: Non-radial directional performance measurement with undesirable output. Omega, $40(1), 1-8$. 
Berg, S. A., Førsund, F. R., \& Jansen, E. S. (1992). Malmquist indices of productivity growth during the deregulation of Norwegian banking, 1980-89. The Scandinavian Journal of Economics, 94, 211-228.

Blancard, S., Boussemart, J.-P., Briec, W., \& Kerstens, K. (2006). Short-and long-run credit constraints in French agriculture: A directional distance function framework using expenditure-constrained profit functions. American Journal of Agricultural Economics, 88(2), 351-364.

Boyd, G. A., \& McClelland, J. D. (1999). The Impact of Environmental Constraints on Productivity Improvement in Integrated Paper Plants. Journal of Environmental Economics and Management, 38(2), 121-142.

Bruni, M., Guerriero, F., \& Patitucci, V. (2011). Benchmarking Sustainable Development via Data envelopment Analysis: an Italian case study. Int. J. Environ. Res, 5(1), 47-56.

Burnett, R. D., \& Hansen, D. R. (2008). Ecoefficiency: Defining a role for environmental cost management. Accounting, Organizations and Society, 33(6), 551-581.

Chambers, R. G., Chung, Y., \& Färe, R. (1996). Benefit and Distance Functions. Journal of Economic Theory, 70(2), 407-419.

Charnes, A., Cooper, W., \& Rhodes, E. (1978). Measuring the efficiency of decision making units. European journal of operational research, 2(6), 429-444.

Chen, Y., Du, J., \& Huo, J. (2013). Super-efficiency based on a modified directional distance function. Omega, 41(3), 621-625.

Chung, Y. H., Färe, R., \& Grosskopf, S. (1997). Productivity and Undesirable Outputs: A Directional Distance Function Approach. Journal of Environmental Management, 51(3), 229-240.

Coli, M., Nissi, E., \& Rapposelli, A. (2011). Efficiency Evaluation in an Airline Company: Some Empirical Results. Journal of Applied Sciences, 11(4), 737-742. 
Cook, W. D., \& Seiford, L. M. (2009). Data envelopment analysis (DEA) - Thirty years on. European Journal of Operational Research, 192(1), 1-17.

Emrouznejad, A., Parker, B. R., \& Tavares, G. (2008). Evaluation of research in efficiency and productivity: A survey and analysis of the first 30 years of scholarly literature in DEA. Socio-Economic Planning Sciences, 42(3), 151-157.

Färe, R., \& Grosskopf, S. (2000). Theory and application of directional distance functions. Journal of productivity analysis, 13(2), 93-103.

Färe, R., \& Grosskopf, S. (2010a). Directional distance functions and slacks-based measures of efficiency. European journal of operational research, 200(1), 320-322.

Färe, R., \& Grosskopf, S. (2010b). Directional distance functions and slacks-based measures of efficiency: Some clarifications. European journal of operational research, 206(3), 702.

Färe, R., \& Grosskopf, S. (2013). DEA, directional distance functions and positive, affine data transformation. Omega, 41(1), 28-30.

Färe, R., Grosskopf, S., Noh, D. W., \& Weber, W. (2005). Characteristics of a polluting technology: theory and practice. Journal of Econometrics, 126(2), 469-492.

Färe, R., Grosskopf, S., Norris, M., \& Zhang, Z. (1994). Productivity growth, technical progress, and efficiency change in industrialized countries. The American Economic Review, 6683.

Färe, R., Grosskopf, S., \& Pasurka, J. C. A. (2007). Environmental production functions and environmental directional distance functions. Energy, 32(7), 1055-1066.

Färe, R., Grosskopf, S., \& Pasurka Jr, C. A. (2001). Accounting for air pollution emissions in measures of state manufacturing productivity growth. Journal of Regional Science, 41(3), 381-409.

Färe , R., Grosskopf, S., \& Pasurka Jr, C. A. (2007). Environmental production functions and environmental directional distance functions. Energy, 32(7), 1055-1066. 
Farrell, M. J. (1957). The measurement of productive efficiency. Journal of the Royal Statistical Society. Series A (General), 120(3), 253-290.

Fukuyama, H., \& Weber, W. L. (2010). A slacks-based inefficiency measure for a two-stage system with bad outputs. Omega, 38(5), 398-409.

Fukuyama, H., Yoshida, Y., \& Managi, S. (2011). Modal choice between air and rail: a social efficiency benchmarking analysis that considers $\mathrm{CO} 2$ emissions. Environmental Economics and Policy Studies, 13(2), 89-102.

Ghazizadeh, M. S., Sheikh-El-Eslami, M. K., \& Seifi, H. (2007). Electricity restructuring [Business Scene]. Power and Energy Magazine, IEEE, 5(2), 16-20.

Golany, B., Roll, Y., \& Rybak, D. (1994). Measuring efficiency of power plants in Israel by data envelopment analysis. Engineering Management, IEEE Transactions on, 41(3), 291-301.

Knox Lovell, C. A., Pastor, J. T., \& Turner, J. A. (1995). Measuring macroeconomic performance in the OECD: A comparison of European and non-European countries. European journal of operational research, 87(3), 507-518.

Korhonen, P. J., \& Luptacik, M. (2004). Eco-efficiency analysis of power plants: An extension of data envelopment analysis. European journal of operational research, 154(2), 437446.

Kortelainen, M. (2008). Dynamic environmental performance analysis: A Malmquist index approach. Ecological Economics, 64(4), 701-715.

Kortelainen, M., \& Kuosmanen, T. (2007). Eco-efficiency analysis of consumer durables using absolute shadow prices. Journal of productivity analysis, 28(1), 57-69.

Kuosmanen, T., \& Kazemi Matin, R. (2011). Duality of weakly disposable technology. Omega, 39(5), 504-512. 
Mahlberg, B., \& Sahoo, B. K. (2011). Radial and non-radial decompositions of Luenberger productivity indicator with an illustrative application. International Journal of Production Economics, 131(2), 721-726.

Oggioni, G., Riccardi, R., \& Toninelli, R. (2011). Eco-efficiency of the world cement industry: A data envelopment analysis. Energy Policy, 39(5), 2842-2854.

Oh, D. (2010). A global Malmquist-Luenberger productivity index. Journal of productivity analysis, 34(3), 183-197.

Oude Lansink, A., \& Bezlepkin, I. (2003). The effect of heating technologies on CO2 and energy efficiency of Dutch greenhouse firms. Journal of Environmental Management, 68(1), 7382.

Picazo-Tadeo, A. J., Reig-Martínez, E., \& Hernández-Sancho, F. (2005). Directional distance functions and environmental regulation. Resource and Energy Economics, 27(2), 131142.

Ray, S. C. (2007). The directional distance function and measurement of super-efficiency: an application to airlines data. Journal of the Operational Research Society, 59(6), 788-797.

Sahoo, B. K., Luptacik, M., \& Mahlberg, B. (2011). Alternative measures of environmental technology structure in DEA: An application. European Journal of Operational Research, 215(3), 750-762.

Scheel, H. (2001). Undesirable outputs in efficiency valuations. European journal of operational research, 132(2), 400-410.

Seiford, L. M. (1996). Data envelopment analysis: The evolution of the state of the art (19781995). Journal of productivity analysis, 7(2), 99-137.

Seiford, L. M., \& Zhu, J. (2002). Modeling undesirable factors in efficiency evaluation. European journal of operational research, 142(1), 16-20. 
Shephard, R. W., Gale, D., \& Kuhn, H. W. (1970). Theory of cost and production functions: Princeton University Press Princeton.

Sueyoshi, T., \& Goto, M. (2011). DEA approach for unified efficiency measurement: Assessment of Japanese fossil fuel power generation. Energy Economics, 33(2), 292-303.

Sueyoshi, T., \& Goto, M. (2013). Returns to scale vs. damages to scale in data envelopment analysis: An impact of U.S. clean air act on coal-fired power plants. Omega, 41(2), 164175.

Tone, K. (2001). A slacks-based measure of efficiency in data envelopment analysis. European journal of operational research, 130(3), 498-509.

Tone, K. (2010). Variations on the theme of slacks-based measure of efficiency in DEA. European journal of operational research, 200(3), 901-907.

Tyteca, D. (1996). On the Measurement of the Environmental Performance of Firms-- A Literature Review and a Productive Efficiency Perspective. Journal of Environmental Management, 46(3), 281-308.

Tyteca, D. (1997). Linear programming models for the measurement of environmental performance of firms - concepts and empirical results. Journal of productivity analysis, $8(2), 183-197$.

Wang, H., Zhou, P., \& Zhou, D. Q. (2013). Scenario-based energy efficiency and productivity in China: A non-radial directional distance function analysis. Energy Economics, 40(0), 795-803.

Yawe, B., \& Kavuma, S. (2008). Technical efficiency in the presence of desirable and undesirable outputs: a case study of selected district referral hospitals in Uganda. Health Policy and Development, 6(1), 37-53.

Zaim, O., \& Taskin, F. (2000). Environmental efficiency in carbon dioxide emissions in the OECD: A non-parametric approach. Journal of Environmental Management, 58(2), 95107. 
Zhou, P., Ang, B. W., \& Han, J. Y. (2010). Total factor carbon emission performance: A Malmquist index analysis. Energy Economics, 32(1), 194-201.

Zhou, P., Ang, B. W., \& Poh, K. L. (2006). Slacks-based efficiency measures for modeling environmental performance. Ecological Economics, 60(1), 111-118.

Zhou, P., Ang, B. W., \& Wang, H. (2012). Energy and CO2 emission performance in electricity generation: A non-radial directional distance function approach. European Journal of Operational Research, 221(3), 625-635.

Zhou, P., Poh, K. L., \& Ang, B. W. (2007). A non-radial DEA approach to measuring environmental performance. European journal of operational research, 178(1), 1-9. 


\section{Appendix}

\section{Example 1}

Contemporaneous Malmquist-Luenberger index and Global Malmquist-Luenberger index are indeed different measures with their own applications, so comparing these two measures may be seriously questionable.

We use a set of 6 DMU's with equal inputs and just one good and one bad output as exhibited in the following table:

Table A1: A Set of 6 DMU's used to show the global ML deficiencies

\begin{tabular}{c|cc|cc}
\multirow{2}{*}{ DMU } & \multicolumn{2}{|c|}{1} & \multicolumn{2}{c}{2} \\
\cline { 2 - 5 } Period & $\mathrm{z}$ & $\mathrm{y}$ & $\mathrm{z}$ & $\mathrm{y}$ \\
\hline 1. & 2 & 1 & 3 & 3 \\
2. & $\frac{10-4 \sqrt{5}}{5}$ & $\frac{4 \sqrt{10 \sqrt{5}+4}}{5}$ & $\frac{10-4 \sqrt{5}}{5}$ & $\frac{4 \sqrt{10 \sqrt{5}+4}}{5}$ \\
3. & $3-\sqrt{2}$ & $3+\sqrt{2}$ & 3 & 2 \\
4. & 5 & 6 & 8 & 4 \\
5. & 8 & 6 & 7 & 3 \\
6. & 10 & 5 & 10 & 5
\end{tabular}

Using DDF model (Model (7)), and DMU's presented in Table A1, we can draw the following diagram: 


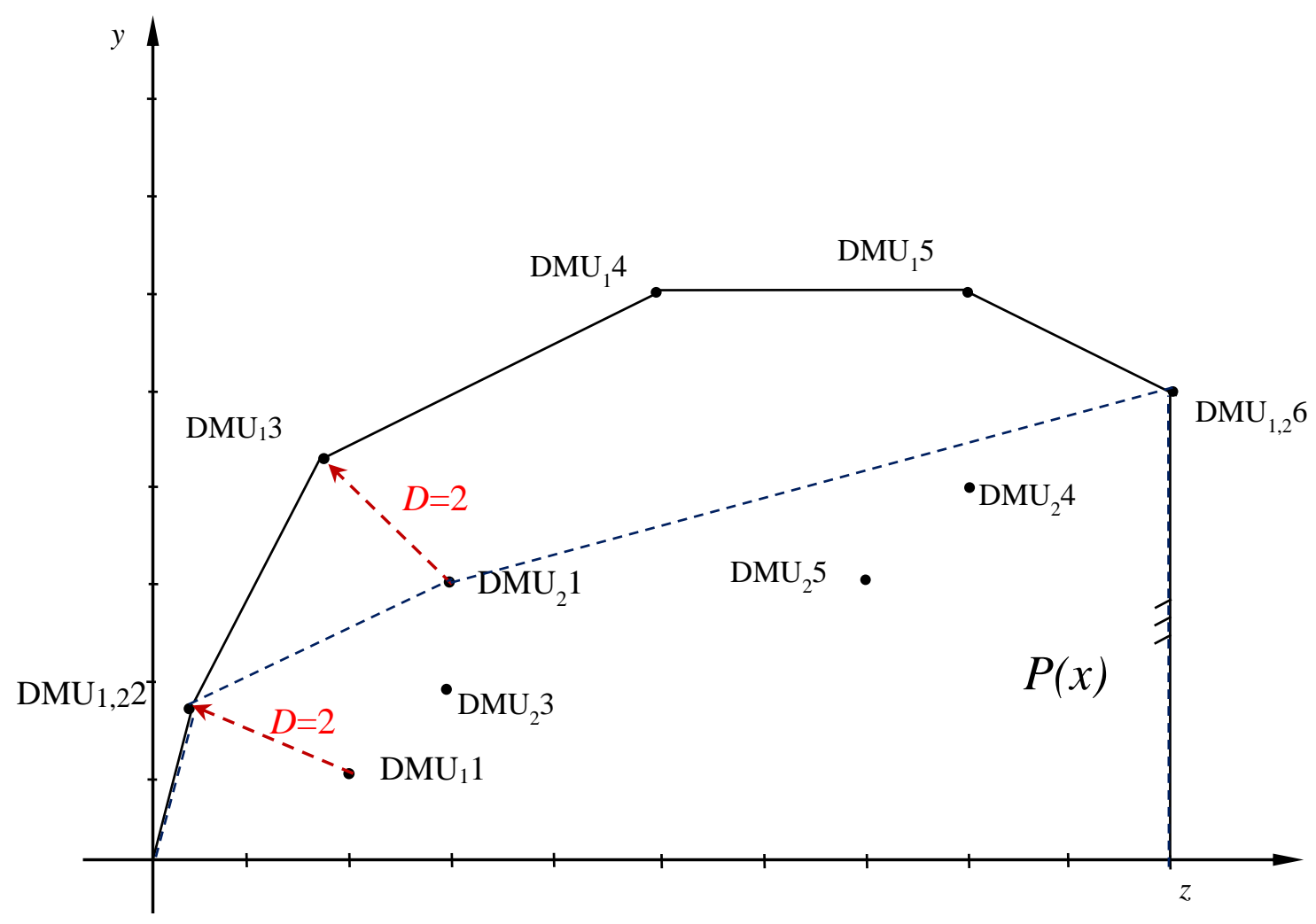

Figure A1: Graphical presentation of DMUs in Table A1 using DDF frontiers

In Figure A1, the frontier composed of $\mathrm{DMU}_{1,2} 2, \mathrm{DMU}_{1} 3, \mathrm{DMU}_{1} 4, \mathrm{DMU}_{1} 5$, and $\mathrm{DMU}_{1,2} 6$ (black line) represents the technology frontier for period 1, and the frontier composed of $\mathrm{DMU}_{1,22}, \mathrm{DMU}_{2} 1$, and $\mathrm{DMU}_{1,2} 6$ (blue dotted line) represents the technology frontier for period 2. By using the DDF technique to compute the Global ML index for $\mathrm{DMU}_{1}$ for both periods, distance $(D)$ to the frontier provides an index equal to 1 . Thus, we obtain the following:

$$
\mathrm{ML}^{\mathrm{G}}=\sqrt{\frac{1+2}{1+2}}=1
$$

On the other hand, in the case of the contemporaneous ML, $M L_{1}^{2}$ we have:

$$
\mathrm{ML}_{1}^{2}=\sqrt{\frac{1+2}{1+0} \cdot \frac{1+2}{1+2}}=\sqrt{3}=1.73
$$

As it is obvious from the data, $\mathrm{DMU}_{1}$ has had a clear improvement from period 1 to period 2 because in period 1 it has produced more bads in comparison with goods whereas in period 2 it 
has produced as much bads as goods. In addition, in period 1, DMU 1 was inefficient, but in period 2 it is efficient. Therefore, on both counts, DMU1 has improved, but the Global Malmquist-Luenberger index has failed to show this improvement indicating no change in ecoefficiency.

To summarize, Global Malmquist-Luenberger index is not a proper measure to compute the contemporaneous Malmquist-Luenberger and to show the trend. In fact, these are two different measures, and the approach in Oh (2010) cannot be a proper solution for the infeasibility problem.

\section{Example 2}

We borrow the example drawn in Aparicio et al. (2013) and customize it to show the shortcoming of the approach introduced to tackle the infeasibility problem in the same paper.

Table A2: Data

\begin{tabular}{cccc}
\hline DMU & $x$ & $y$ & $b$ \\
\hline$A^{t}$ & 1 & 7 & 2 \\
$B^{t}$ & 1 & 5 & 5 \\
$A^{t+1}$ & 1 & 6.5 & 1 \\
$B^{t+1}$ & 1 & 5.5 & 3 \\
\hline
\end{tabular}




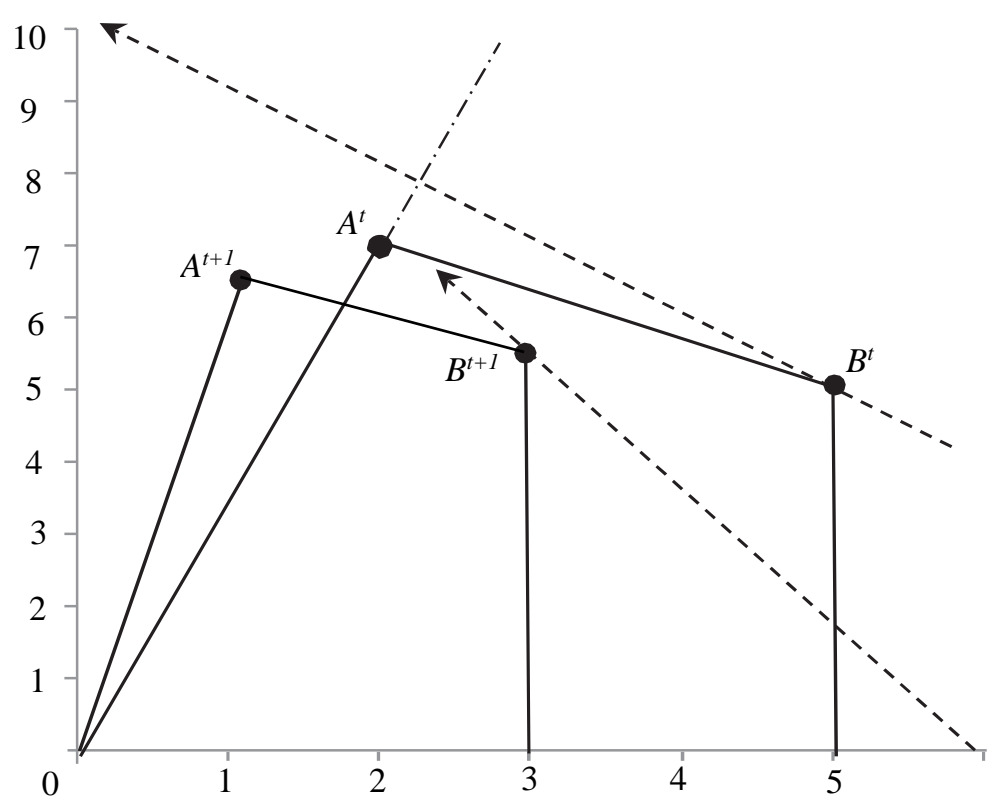

Figure A2: Output sets in $t$ and $t+1$ (good and bad outputs)

As can be seen in the above Figure, Model (7) will be infeasible when $\mathrm{ML}_{t+1}^{t}$ for $B^{t}$ and $A^{t}$ are calculated. Now, if we deploy the approach introduce by Aparicio et al. (2013), we can draw the problem in the following Figure.

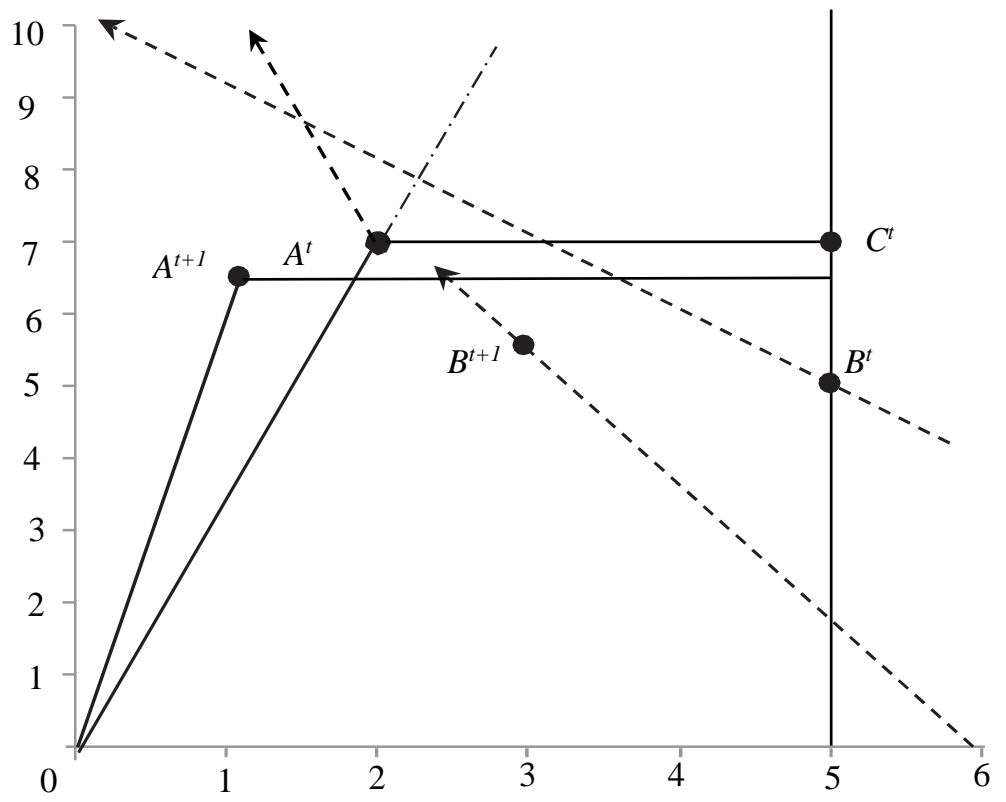

Figure A3: New output sets in $t$ and $t+1$ from new approach

It is clearly seen in Figure 3, although $\mathrm{ML}_{t+1}^{t}$ is feasible for $B^{t}$, but it still infeasible for $A^{t}$, since the direction arrow corresponding to $A^{t}$ does not intersect any of the production possibility sets in 
period $t+1$. In fact, the approach fails to build nested production possibility sets corresponding to the consecutive periods as argued in this paper.

In addition in Figure, $C^{t}=(7,5)$ is a feasible DMU (virtual) by the approach introduced in Aparicio et al. (2013). $C^{t}$ in comparison to $A^{t}=(7,2)$ produces significantly more undesirable output (5-2=3) using same amount of input and producing same amount of desirable output. This situation clearly contradicts the null jointness property. $C^{t}$ indicates 3 units of extra undesirable outputs produced accompanying with the 0 amount of extra output, which is not happened in the real world using the existing technology which is used by $A$ and $B$ in two consecutive periods, $t$ and $t+1$. This is while, $C^{t}$ and its convex combination with $A^{t}$ are employed to form the efficiency frontier.

Furthermore, using the approach proposed in Aparicio et al. (2013) it clear that $B^{t}$, which used to be an efficient DMU, is determined as an inefficient DMU (as it is compared with a frontier that is drawn based on convex combination of two DMU's in which one of them, $C^{t}$, is unreal hypothetical DMU). Indeed, $C^{t}$ in comparison to $B^{t}$ use the same amount of input and produces the same quantity of undesirable output accompanying more 2 units of good output, which is not possible using the concurrent technology deployed by $A$ and $B$ in two consecutive periods, $t$ and $t+1$. 